\title{
Empreendedorismo na ótica da teoria ator-rede: explorando alternativa às perspectivas subjetivista $e$ objetivista
}

\author{
Entrepreneurship from the actor-network theory perspective: exploring alternatives beyond \\ the subjectivism and objectivism
}

\author{
Dany Flávio Tonelli ${ }^{1}$ \\ Mozar José de Brito \\ André Luiz Zambalde ${ }^{3}$
}

\section{Resumo}

Analisar o empreendedorismo explorando as implicações dos pressupostos teórico-metodológicos que a Teoria AtorRede (TAR) oferece. Numa visão geral, foram consideradas duas perspectivas teóricas para o empreendedorismo: uma subjetivista e outra objetivista. A perspectiva subjetivista privilegia o indivíduo, juntamente com suas habilidades e capacidades inerentes. Em menor evidência na literatura, a perspectiva objetivista privilegia os aspectos materiais do ambiente como causas do empreendedorismo. Considerando ambas, a principal limitação está no pouco valor que cada lado dedica à influência do outro na análise geral das iniciativas empreendedoras, o que revela assimetria. Esta limitação abriu espaço para a inserção da Teoria Ator-Rede (TAR). Ao desconsiderar a dualidade imposta pelas perspectivas iniciais, a TAR permitiu explorar novas possibilidades de compreensão por meio do conceito de simetria (BLOOR, 1976; LATOUR, 2005; LATOUR e WOOLGAR, 1997). Com base nisso, a TAR considera todas as entidades híbridas, compostas ao mesmo tempo de subjetividade e de objetividade indissociáveis. Isso vai contra o modo assimétrico de tratar a realidade, o qual reproduz uma visão dual, mesmo reconhecendo que ambos os aspectos, subjetivos e objetivos, contribuem para o sucesso ou o insucesso das iniciativas empreendedoras. Entendido dessa forma, o emprendedorismo requer a mobilização de diversos agenciamentos em torno de si, mediante o recrutamento de aliados que passam a integrar um movimento negociado, que requer translação constante de interesses. $O$ descortinar desse movimento revela multiplicidade de relações que envolvem, por exemplo, elementos políticos, sociais, econômicos, culturais, científicos, tecnológicos e os próprios protagonistas que, na história contada, habitualmente são considerados empreendedores.

Palavras-Chave: Empreendedorismo. Teoria Ator-Rede. Simetria. David Bloor. Bruno Latour.

Artigo submetido em 12 de julho de 2010 e aceito para publicação em 26 de novembro de 2010.

1

Mestre em Administração pela Universidade Federal de Lavras (UFLA); Professor assistente da UFLA. Endereço: UFLA Departamento de Administração e Economia (DAE) - Campus Universitário, Caixa postal: 3037, CEP 37200-000, Lavras, MG, Brasil. E-mail: danytonelli@dae.ufla.br

2 Doutor em Administração pela Universidade de São Paulo (USP); Professor associado da UFLA. Endereço: UFLA/DAE - Campus Universitário, Caixa postal: 3037, CEP 37200-000, Lavras, MG, Brasil. E-mail: mozarjdb@dae.ufla.br

${ }^{3}$ Doutor Engenharia de Sistemas e Computação - COPPE/UFRJ; Professor associado da UFLA. Endereço: UFLA - Departamento de Ciência da Computação (DCC) - Campus Universitário, Caixa postal: 3037, CEP 37200-000, Lavras, MG, Brasil. E-mail: zamba@dcc.ufla.br 


\begin{abstract}
This paper aims to analyze entrepreneurship by exploring the theoretical and methodological implications proposed by the Actor-Network Theory (ANT). Broadly speaking, we considered two theoretical perspectives for entrepreneurship: the subjectivist and the objectivist. The subjectivist perspective emphasizes the individual, with his skills and inherent abilities. Less explored in the literature, the objectivist perspective emphasizes the material aspects of the environment that cause entrepreneurship. Considering both, the main limitation is the little importance that each side gives to the influence of the other in the overall analysis of the processes. This theoretical evidence reveals asymmetries, which display the insertion of the ANT application. Disregarding the duality imposed by the initial perspectives, the ANT enabled the exploration of new possibilities for understanding through the concept of "symmetry" (BLOOR 1976; LATOUR 2005; LATOUR e WOOLGAR, 1997). In this way, the ANT considers all entities as hybrids: they are formed at the same time from subjectivity and objectivity. This argument is divergent with the asymmetric way of accessing the reality, which reproduces a dual vision of it, even recognizing that both subjective and objective aspects contribute to the success or failure of entrepreneurial initiatives. Thus, entrepreneurship requires the mobilization of diverse assemblages around itself, which necessitates the gathering of several allies who will be part of a negotiated movement and translations of interests. Uncovering this movement reveals the multiplicity of relationships that involves, for instance, political, social, economic, cultural, scientific and technological factors, as well as the protagonists who, in history, usually are considered entrepreneurs.
\end{abstract}

Key-words: Entrepreneurship. Actor-Network Theory. Symmetry. David Bloor. Bruno Latour.

\title{
Introdução
}

O interesse pelo empreendedorismo está em plena ascensão. Como tema promissor, ele vem atraindo pesquisadores oriundos de diversas áreas científicas: das Ciências Sociais às Ciências Jurídicas, passando pela Psicologia, Economia e Administração. Em todas as áreas, abordar empreendedorismo e seu impacto em dinâmicas distintas da sociedade constitui alvo comum. Entretanto, ao mesmo tempo em que possibilitou a disseminação do uso do conceito, isso também influenciou para sua maior fluidez (POZEN, 2008). Com efeito, a compreensão mais ampliada do empreendedorismo se desenvolve ao lado da busca por mais consolidação teórica desta temática marcada pela transdisciplinaridade. Pretendendo seguir nessa direção, exploram-se, neste artigo, novas possibilidades teóricas e metodológicas que possibilitem contribuição adicional. No nosso entendimento, esse movimento passa pela superação das assimetrias que ainda marcam as perspectivas correntes acerca do empreendedorismo.

O objetivo, aqui, é analisar o empreendedorismo explorando as implicações dos pressupostos teóricometodológicos da Teoria Ator-Rede (TAR). Tal teoria alinha-se ao que Peci e Alcadipani (2006) chamaram de construtivismo crítico, uma vez que procura rever criticamente as premissas do construtivismo social, especialmente a ênfase sobre o adjetivo social. Isso permite à TAR romper com a noção de realidades representadas por uma visão dualizada de mundo, por meio da qual se trata de modo assimétrico a natureza e a sociedade. Assim, a TAR possibilita análises menos influenciadas por polarizações voluntaristas versus estruturalistas, herdadas da grande tradição sociológica. Mais do que uma ruptura teórica, a TAR oferece uma ruptura metodológica, visto que possibilita um olhar descritivo sobre o fenômeno mediante lentes que permitem reconhecer que a ação e o movimento integram concomitantemente humanos (sociedade) e não humanos (natureza) de modo simétrico (LATOUR e WOOLGAR, 1997).

Antes de explorar mais a fundo o objetivo central deste trabalho, duas perspectivas foram consideradas: uma subjetivista e outra objetivista. Elas permitem uma visão geral e parcial acerca do estado da arte sobre o empreendedorismo. A perspectiva subjetivista dedica maior importância à figura do indivíduo empreendedor. De modo geral, ela focaliza a atuação da pessoa, suas habilidades, suas capacidades inerentes e a construção de sua identidade (self). Desse ponto de vista, o comportamento empreendedor vem de dentro 
para fora, seja como manifestação de impulsos naturais, seja como o resultado de experiências acumuladas. Pela importância que ocupa, essa perspectiva constitui o coração do empreendedorismo (KOR, MAHONEY e MICHAEL, 2007).

Em menor evidência na literatura, embora não menos importante, está a segunda perspectiva, a objetivista, cujo mérito está no fato de ela colocar no centro das causas do empreendedorismo os aspectos materiais do ambiente onde ocorrem as iniciativas empreendedoras. Sob esse olhar, o contexto assume importância fundamental. Da ênfase nas estruturas decorre a noção de que determinados contextos materiais específicos criam as condições para o surgimento dos processos empreendedores. $\mathrm{E}$ isso acontece, muitas vezes, por razões acidentais, resultantes da combinação de tempo e lugar apropriados (GÖRLING e REHN, 2008). Outra possibilidade dessa perspectiva é valorizar a ação estratégica de criação de ambientes favoráveis ao empreendedorismo. Um exemplo está na evidência de que spin-offs universitárias promovem empreendedorismo acadêmico (COSTA e TORKOMIAN, 2008). Uma visão geral dessa perspectiva permite perceber que o comportamento empreendedor é produto do meio, ou seja, acontece de fora para dentro.

Em ambas as perspectivas, verifica-se uma principal limitação: o tratamento assimétrico que ambas dedicam aos elementos subjetivo e objetivo. Isso se traduz na curta apreciação que cada lado faz acerca da influência do outro na compreensão do empreendedorismo. Essa limitação abriu espaço para a inserção de outra perspectiva, orientada pela Teoria Ator-Rede (TAR). Esta, ao desconsiderar a dualidade imposta pelas perspectivas iniciais, permitiu a exploração de novas possibilidades. De modo geral, a TAR rejeita os essencialismos por meio do conceito de simetria entre subjetividade e objetividade. Isso conduz a algumas importantes implicações teóricas e metodológicas. Após explorar esse novo arcabouço, apontando as principais contribuições do estudo, são apresentadas algumas reflexões, limitações e sugestões para futuras pesquisas.

\section{A perspectiva subjetivista}

A perspectiva subjetivista dedica maior importância à figura do indivíduo empreendedor. De modo geral, ela focaliza a atuação da pessoa, suas habilidades, suas capacidades inerentes e a construção de sua identidade (self). Desse ponto de vista, o comportamento empreendedor vem de dentro para fora, seja como manifestação de impulsos naturais, seja como o resultado de experiências acumuladas. Pela importância que ocupa, essa perspectiva constitui o coração do empreendedorismo (KOR, MAHONEY e MICHAEL, 2007).

Isso leva à identificação de uma premissa básica, a qual está relacionada com o entendimento de que as iniciativas empreendedoras partem do sujeito, de sua inerente capacidade de percepção da realidade e de ação sobre ela (BARROS, FIÚSA e IPIRANGA, 2005; GÖRLING e REHN, 2008; KOR, MAHONEY e MICHAEL, 2007). Dentro da perspectiva subjetivista, podemos encontrar duas abordagens: uma construída no âmbito da economia e outra no âmbito dos estudos comportamentais (BARROS, FIÚSA e IPIRANGA, 2005). Neste trabalho, elas foram designadas como abordagem economicista e abordagem comportamentalista. Na abordagem economicista, a preocupação está centrada nos resultados da atuação empreendedora e seus reflexos nas economias de mercado. $\mathrm{Na}$ abordagem comportamentalista, a preocupação está na busca por compreensão sobre a possibilidade de construção e o grau de inerência das habilidades do sujeito (self) empreendedor.

A abordagem economicista se firmou em torno do papel do empreendedor na economia. Ela tem origem nos trabalhos dos economistas Richard Cantilon (1680-1734), Jean-Baptiste Say (1767-1832) e Joseph Schumpeter (1883-1950) (BARROS, FIÚSA e IPIRANGA, 2005; POZEN, 2008). Em grande parte, ela coloca em evidência os benefícios advindos da prática empreendedora para a manutenção e o crescimento das economias de mercado. Exemplo disso está no fato de Schumpeter posicionar o empreendedor como um criador de ordem na economia, restringindo, com sua atuação, o efeito das assimetrias de informação e das 
ineficiências de mercado (GÖRLING e REHN, 2008). Percebe-se que o foco está no resultado da ação. Na opinião de Kor, Mahoney e Michael (2007), a ação empreendedora tem importância fundamental para as firmas e as agências governamentais, uma vez que em torno dela se encontram as dinâmicas do capitalismo moderno, são criados os investimentos, introduzidas novas tecnologias e melhorados os padrões de vida e bem-estar das pessoas (KOR, MAHONEY e MICHAEL, 2007).

Algumas formulações teóricas foram influenciadas por boa parte da abordagem economicista. A primeira delas, de acordo com Salem (2006) e Pozen (2008), está relacionada com a tendência em considerar empreendedor o empresário que inicia e organiza um empreendimento, administra de forma eficiente, atrai clientes e gera receita. Outro aspecto se relaciona com a predisposição do empreendedor para assumir riscos, investindo geralmente capital próprio e reputação em torno de uma ideia. Ao lado dessas características, encontra-se um conjunto de símbolos. No imaginário coletivo, criou-se a ideia do empresário como líder, inovador, pioneiro, aquele que soluciona problemas e assume riscos. Ele manifesta, como atributos inerentes ao seu caráter, a diligência, a persistência, o carisma, o dinamismo e a criatividade. Uma compreensão sobre o "espírito empreendedor" necessariamente passa pelo resgate dos símbolos do guerreiro e do herói modernos (POZEN, 2008; SALEM, 2006).

O fenômeno da atuação empreendedora na abordagem economicista - visto da ótica da metáfora de Latour (2000) - é uma caixa-preta. Não há a preocupação em abrir a caixa e entender a origem da atuação empreendedora, nem como ela se manifesta nas pessoas e nas coisas, permanecendo apenas a ideia do empreendedor como um sujeito que, conforme Barros, Fiúsa e Ipiranca (2005), possui qualidades naturais que o destacam nos negócios. Em outras palavras, a existência de pessoas com habilidades e competências extraordinárias na transformação de ideias em atitudes inovadoras, as quais repercutem positivamente na economia, é um fato. Como afirma Salem (2006), assim como os artesãos que herdavam e desenvolviam habilidades manuais as quais permitiam lidar com os modos de produção da Idade Média, os empreendedores são vistos como privilegiados detentores de capacidades singulares para o comércio e a indústria, ocupando, assim, lugar de destaque na promoção do desenvolvimento do capitalismo.

Como exemplo dessa abordagem está o estudo de Kor, Mahoney e Michael (2007). Com base na noção de que o empreendedorismo é um fenômeno que surge por meio de habilidades intrínsecas do sujeito, os autores afirmam que ele deve ser compreendido mediante a ação humana propositada e inovadora dentro de um espaço social. Essa ação não estaria necessariamente relacionada apenas com abertura de novas firmas, mas também com o fato de empregados poderem oferecer uma diversidade de serviços às organizações, como a idealização de novos produtos, introdução de novos processos administrativos e outros que efetivamente contribuem para a eficiência organizacional (KOR, MAHONEY e MICHAEL, 2007). Essa perspectiva, embora muito disseminada, também é muito criticada. Hjorth (2005), por exemplo, afirma que a abordagem economicista marginaliza questões artísticas da criatividade, fortalecendo um olhar gerencialista e objetivista sobre um processo eminentemente subjetivista. Com isso, a abordagem economicista menospreza, por exemplo, a capacidade de os empregados subverterem a ordem estrita dos discursos sobre criatividade como produção de resultados maximizados (HJORTH, 2005).

A segunda abordagem da perspectiva subjetivista é a comportamentalista. Essa perspectiva busca responder (i) por que alguns indivíduos manifestam maior disposição ao empreendedorismo do que outros e (ii) se essas habilidades podem ser aprendidas. Desse ponto de vista, diversos métodos têm sido desenvolvidos com o objetivo de mensurar a predisposição psicológica de indivíduos para o empreendedorismo (MARCATI, GUIDO e PELUSO, 2008). Uma das formas utilizadas está na identificação da capacidade de inovar de uma pessoa. Para Marcati e seus colaboradores, tal capacidade é um componente intrínseco do caráter humano e está relacionada com a personalidade empreendedora. A personalidade humana é entendida como um esquema de respostas de um indivíduo a um ambiente e pode ser vista como um construto de imagens inter e intraindividuais, as quais tendem a ser relativamente estáveis no decorrer do tempo (MARCATI, GUIDO e PELUSO, 2008). 
Numa visão um pouco distinta da ideia de inovatividade como atributo intrínseco do caráter humano, há também a noção de que o comportamento empreendedor pode ser aprendido com a experiência e os estímulos externos. A respeito desse processo de construção do self empreendedor por estímulos externos, David McClelland (MCCLELLAND, 1961) oferece grande contribuição. O autor buscava respostas para questões relacionadas com o motivo do sucesso dos imigrantes chineses no comércio do sudeste asiático ou com a rapidez com que judeus se elevavam socialmente nos Estados Unidos. Partindo disso, McClelland afirmava haver três necessidades básicas, variáveis de cultura para cultura, chamadas de necessidade de realização; necessidade de poder e necessidade de afiliação (MCCLELLAND, 1961). Utilizadas para explicar a formação do comportamento empreendedor, essas necessidades, quando potencializadas ou limitadas, também potencializariam ou limitariam atitudes empreendedoras por parte de indivíduos.

De modo geral, a perspectiva subjetivista do empreendedorismo, especialmente aquela que decorre da abordagem comportamentalista, sugere uma conexão causal entre criatividade e desenvolvimento de aprendizado pelas pessoas empreendedoras por intermédio de dinâmicas variadas dos processos sociais (KOR, MAHONEY e MICHAEL, 2007). Além disso, Kor, Mahoney e Michael (2007) chamam a atenção para outro aspecto relacionado à capacidade do empreendedor: o de não apenas perceber oportunidades existentes, mas também criar oportunidades por meio de suas interações com clientes, tecnologias e outros stakeholders. É importante frisar que, na perspectiva subjetivista, ambas as abordagens compartilham uma premissa em comum. Essa premissa está relacionada com a compreensão de que iniciativas empreendedoras são dirigidas por ações humanas intencionais e metaorientadas (GÖRLING e REHN, 2008).

A predominância da perspectiva subjetivista acarreta alguns problemas. No que se refere à criatividade, o foco dos estudos tem sido direcionado à busca de como aumentar os resultados e a utilidade da criatividade organizacional e não em descrever as complexidades do processo criativo. Nessa perspectiva, a criatividade tem como meta manipular as variáveis do contexto para maximizar os resultados e a utilidade (DRIVER, 2008). O autor faz uma imersão na teoria psicanalítica com o objetivo de investigar como os discursos sobre criatividade produzem e são produzidos pela atuação consciente e inconsciente das pessoas na construção de sua subjetividade. Os argumentos desenvolvidos pela autora sugerem a exploração dos espaços, os quais não são apenas físicos, mas também discursivos, por meio dos quais tem sido possível refletir sobre como as pessoas percebem as outras. A complexidade envolta no processo de criatividade produzido por espaços de interação entre pessoas criativas e outras que passam a ter acesso a essa criatividade, embora de modo nenhum promova um afastamento da perspectiva subjetivista, inicia uma abertura de possibilidades de exploração com os processos coletivos de geração de criatividade, em vez do foco centrado nas habilidades criativas individuais (DRIVER, 2008).

Além de se afastarem da abordagem subjetivista, alguns autores promovem duras críticas a ela. Para Görling e Rehn (2008), por exemplo, o maior problema do discurso subjetivista decorre da manutenção da ideia arquetípica voltada à compreensão da ação do agente empreendedor. Nesse enfoque, a ação é idealizada em virtude da capacidade que a pessoa empreendedora tem em identificar oportunidades e em agir intencionalmente na concretização de ideias ou na introdução de novos negócios no mercado (GÖRLING e REHN, 2008). Na opinião desses autores (p. 94), esse fato reduz o campo de estudos sobre o empreendedorismo em torno dos limites impostos por conceitos como potencial, oportunidade e descoberta. O uso irrefletido e idealístico desses conceitos limita o avanço do campo do empreendedorismo, cuja compreensão, portanto, deve passar inclusive pela perspectiva objetivista, a qual focaliza o outro lado da realidade, o que descortinaria possibilidades plenas para avanços (GÖRLING e REHN, 2008).

\section{A perspectiva objetivista}

Em menor evidência na literatura, embora não menos importante, está a segunda perspectiva - a objetivista (GÖRLING e REHN, 2008). A característica mais importante desta perspectiva está no fato de ela colocar 
no centro das causas do empreendedorismo os aspectos materiais do ambiente onde ocorrem as iniciativas empreendedoras.

Enquanto a perspectiva subjetivista coloca o indivíduo no centro das causas do empreendedorismo, a objetivista ocupa-se em entender a manifestação do empreendedorismo com base nas condições materiais a ele relacionadas (COOPER e PARK, 2008; GÖRLING e REHN, 2008). Na literatura econômica, espaços geográficos como os clusters regionais ocupam lugar de destaque no que se refere à potencialização de iniciativas inovadoras e à contribuição que eles efetivamente oferecem ao desenvolvimento econômico (FERRARY e GRANOVETTER, 2009; HUGGINS, 2008; PARTO, 2008; REID, SMITH e CARROLL, 2008). Para Cooper e Park (2008), as condições materiais do contexto revelam campos de interações sociais, de sinergias interpessoais e de ações coletivas que determinam capacidades para a inovação em áreas geográficas específicas. Entretanto, embora haja muitas evidências acerca das influências desses espaços econômicos e relacionais, Cooper e Park (2008) afirmam que não são muitos os estudos que exploram o potencial desses contextos para a compreensão das iniciativas empreendedoras. Na mesma direção, Görling e Rehn (2008) afirmam que são raros os estudos que buscam compreender os processos empreendedores pelas condições materiais que se reproduzem no contexto objetivo onde se inserem.

Depois do enfoque crítico de Görling e Rehn (2008), o conceito de potencial empreendedor tem sido desenvolvido sobre bases que os autores chamam de idealismo metafísico irrefletido. Os fundamentos dessa crítica posicionam-se contra as vertentes eminentemente voltadas para a compreensão de habilidades centradas nas características intrínsecas da pessoa, desconsiderando ou depreciando a importância das condições materiais sob as quais os processos empreendedores acontecem. Göling e Rehn (2008) propõem um deslocamento ontológico (de uma ontologia subjetivista para uma ontologia materialista) a fim de favorecer a compreensão das iniciativas empreendedoras. Isso requer o deslocamento do foco de análise centralizado em torno do sujeito empreendedor para os aspectos materiais e contextuais que cercam o fenômeno do empreendedorismo e favorecem o seu surgimento. O principal argumento tem a ver com a ideia de que empreendedorismo não necessariamente se refere à concepção de uma boa ideia ou à percepção de uma oportunidade, nem à noção da preexistência de um potencial empreendedor do indivíduo. Para Görling e Rehn (2008), seria mais plausível explicar a maioria dos casos de iniciativas empreendedoras de sucesso mediante fenômenos acidentais, circunstâncias ao acaso que reuniram os recursos necessários em tempo e local certos.

A fim de firmar posição ao lado de uma visão materialista, Görling e Rehn (2008) pontuam as principais diferenças entre si mesmos (materialistas) e os idealistas. Ambos os lados divergem sobre a origem fundamental das coisas. Enquanto no materialismo se concebe a realidade como resultante das condições materiais do mundo; no idealismo se entende que a realidade material é vazia sem que antes haja o ato de pensar, o qual molda o mundo e lhe atribui significado (GÖRLING e REHN, 2008). Para esses autores, ao considerar o mundo material como resultado dos discursos, em vez de causa deles, o subjetivismo idealizado privilegiou estudos metafísicos e abstratos do empreendedorismo, contribuindo para um afastamento entre teorias e realidades práticas. Como exemplo, Görling e Rehn (2008) avaliam o conceito de oportunidade. Segundo os autores, a noção de oportunidade esconde uma categoria ontológica. Uma leitura materialista leva ao entendimento de que todas as oportunidades são contingentes e que o termo pode ser usado para representar fenômenos distintos, sem necessariamente significar que deva haver algo que os una. Em outros termos, as oportunidades são apenas representações linguísticas: não existem antes das condições materiais que as geram. Enquanto isso, na perspectiva subjetivista, as oportunidades são preexistentes e a capacidade de percebê-las difere de pessoa para pessoa (GÖRLING e REHN, 2008).

Diversos estudos somam evidências que permitem a compreensão de que o empreendedorismo é fomentado por estímulos resultantes da existência de estruturas ou contextos favoráveis (STUART e DING, 2006; TOOLE e CZARNITZKI, 2007; 2009). Entretanto, Meyer (2003) afirma que, em contextos específicos, há certa limitação dos mecanismos objetivos de estímulo ao empreendedorismo. Eles não são suficientemente eficientes para estimular a criação de uma identidade empreendedora. Tais mecanismos criam, no máximo, 
um padrão de comportamento que pode estar mais associado à noção deliberadamente imposta de empreendedorismo. Meyer (2003) investigou as tentativas de se criar um dado comportamento empreendedor entre cientistas e pesquisadores com o objetivo de fomentar a transferência de conhecimento para o mercado. Os resultados demonstram o alcance limitado dessas políticas governamentais e de estratégias organizacionais. Entretanto, cientistas que a priori não estariam interessados em agir na direção empreendedora podem passar a fazê-lo. Isso habitualmente acontece porque, por meio dos diversos mecanismos de incentivo, começam a perceber avenidas oportunas nas quais podem desenvolver seus interesses mais importantes. Em geral, esses interesses estão relacionados com o avanço da pesquisa científica (MEYER, 2003).

\section{Explorando alternativa às perspectivas subjetivista e objetivista}

Uma alternativa às perspectivas subjetivista e objetivista é oferecida pela Teoria Ator-Rede (TAR), também conhecida como sociologia da translação ${ }^{4}$ (CZARNIAWSKA, 2009). Ao aproximar o foco de onde realmente ocorrem as práticas cotidianas, a TAR procura compreender como elementos heterogêneos se juntam e passam a atuar por meio de redes, configurando as dinâmicas coletivas. A expressão "Ator-Rede", segundo Law (1999), explora a tensão central em relação à noção de "ator" versus "rede", por meio de um oximoro, o qual combina e elimina a distinção entre agência e estrutura. A tensão se perde quando a ideia de "ator-rede" (com hífen) se converte numa "teoria" consistente e eufônica, capaz de ser facilmente disseminada, criticada, aplicada (LAW, 1999) e, também, transformada (LAW, 2003). Como afirma Latour (1999), a TAR não tem o objetivo de superar o clichê estrutura versus agência. Ao contrário disso, a ideia original da TAR não é ocupar posição nesse debate nem superá-lo, mas simplesmente, ignorá-lo (LATOUR, 1999). "Ator-rede" representa uma única entidade circulante, em vez da ideia dualizada entre duas noções, micro versus macro; indivíduo versus estrutura, ou, ainda, subjetivo versus objetivo (LATOUR, 1999).

"Ator-rede" significa a impossibilidade de existência do ator fora da rede. Os atores estão configurados conforme a posição que assumem. A percepção de sua existência só ocorre por meio da ligação com outros elementos humanos e não humanos que constituem a rede. $\mathrm{O}$ fato de estarem imbricados em redes cria identidade aos atores e lhes provê motivações e recursos. Na rede, a priori, todos os atores (inclusive os artefatos tecnológicos) são atuantes. Fora da rede não pode haver atuação (GEELS, 2005).

Assim sendo, a TAR se recusa a aceitar a ideia de que a compreensão dos fenômenos coletivos deve estar localizada dentro dos limites impostos pelas fronteiras das metáforas duais, como, por exemplo, "agência" versus "estrutura" (LAW, 1999). Acerca disso, Law (1999) comenta que os atributos das entidades não são intrínsecos, mas resultantes de suas relações com outras entidades. Vistos dessa forma, os atores (ou todas as entidades atuantes) não têm qualidades inerentes. Elas trazem consigo atributos híbridos e inseparáveis de humanidade e inumanidade; conteúdo e contexto; sociedade e materialidade; atividade e passividade. De um ou outro modo, todas as divisões são descartadas pela TAR.

\footnotetext{
${ }^{4}$ Translação, "em suas conotações linguística e material, refere-se a todos os deslocamentos por entre outros atores cuja mediação é indispensável à ocorrência de qualquer ação. Em lugar de uma rígida oposição entre contexto e conteúdo, as cadeias de translação referem-se ao trabalho graças ao qual os atores modificam, deslocam e transladam seus vários e contraditórios interesses" (LATOUR, 2001, p. 356). Latour (2000, p. 178-199) traz alguns exemplos de situações em que há translação de interesses. Ela pode ocorrer: (i) quando alguém encontra e se associa a outras pessoas que querem a mesma coisa que ela: eu quero o que você quer; (ii) quando certa mobilização desperta interesses comuns em outras pessoas: eu quero; por que você não quer? (iii) quando, às vezes, por ser necessário alcançar um objetivo comum, alguém tem que ceder e se desviar um pouco do seu objetivo inicial: se você se desviasse um pouquinho... (iv) quando há remanejamento de todos os interesses e objetivos iniciais: deslocar objetivos; inventar novos objetivos; inventar novos grupos; tornar invisível o desvio; vencer as provas de atribuição e (v) quando todos os agentes passam a se mobilizar em torno de uma ação coletiva de modo voluntário, contribuindo para a propagação de uma tese no tempo e no espaço: tornar-se indispensável.
} 
Embora a TAR compartilhe alguns de seus posicionamentos principais com ramos do pós-estruturalismo, com movimentos na teoria feminista e com os estudos culturais e antropologia social, Law (1999) chama a atenção para uma característica autêntica - que também ajuda a compreender por que esta teoria insere-se numa linha construtivista crítica. Ele se refere ao fato de que a TAR pode ser compreendida como uma semiótica da materialidade, o que envolve a ideia de que as entidades são produzidas nas relações. Isso se aplica também às relações com os aspectos materiais, diferentemente do que prevê o pós-estruturalismo foucaultiano, que privilegia apenas os aspectos linguísticos e discursivos da realidade. Law (1999) afirma que a ideia de materialidade relacional capta bem a noção ontológica de materialidade implícita na TAR. Essa característica também possibilita afirmar que a TAR apresenta uma ontologia contingencialista: uma alternativa em relação à ontologia relativista e à ontologia materialista (MICHAEL, 1996). Isso acontece porque a TAR considera que a realidade é influenciada tanto por aspectos linguísticos e discursivos quanto por aspectos materiais. Decorre, então, a resignação da TAR em relação ao termo social. No construtivismo social, o adjetivo social e a abordagem como um todo escondem os aspectos não sociais. Isso causa um viés semiótico de desconsiderar o lado não humano e não linguístico dessas dinâmicas 5 .

A ideia de materialidade relacional aproxima-se do conceito de simetria entre elementos humanos e não humanos. Entretanto, até chegar ao ponto de considerar ontologicamente simétricos os humanos e os não humanos, houve a necessidade de generalizar a aplicação da simetria de David Bloor (BLOOR, 1976). O termo "simetria" foi inspirado no Programa Forte de Sociologia do Conhecimento (BLOOR, 1976). Originalmente, ele se relaciona com dois princípios fundamentais para o estudo sociológico das ciências: o princípio de imparcialidade e o princípio da simetria. O primeiro afirma que devem ser explicados todos os lados de dicotomias como verdade e falsidade, racionalidade e irracionalidade e sucesso e falha. Numa visão que considera que a ciência possui uma lógica e uma racionalidade internas, há a tendência de se prover explicações apenas daquilo que é socialmente considerado não verdadeiro, como a irracionalidade e o insucesso. Isso acontece, por exemplo, com a abordagem dos programas de pesquisa de Imre Lakatos (LAKATOS, 1979). Lakatos, ao considerar a existência de uma lógica interna que dirige a consolidação das disciplinas, naturaliza a ideia da existência de uma racionalidade inerente em cada disciplina científica. Ao criticar a história interna da ciência, Bloor (1976, p. 6) afirma:

The general structure of these explanations stands out clearly. They all divide behavior or belief into two types: right and wrong, true or false, rational or irrational. They then invoke causes to explain the negative side of the division. Causes explain error, limitation and deviation. The positive side of the evaluative divide is quite different. Here logic, rationality and truth appear to be their owin explanation. Here causes do not need to be invoked.

O princípio de imparcialidade provê a base para o princípio da simetria. Bloor (1976) afirma que o estilo da explicação deve ser simétrico. A mesma causa explicaria, por exemplo, crenças verdadeiras e crenças falsas. Assim, todas as explicações do desenvolvimento científico devem ser simétricas. Como Latour e Woolgar (1997, p. 23) afirmaram, é assimétrico "fazer sociologia para compreender por que os franceses acreditam na astrologia, mas não para compreender por que eles acreditam na astronomia". Assim também é assimétrico "fazer sociologia para entender o medo que os franceses têm do átomo, mas não fazê-la para a descoberta do átomo pelos físicos nucleares".

\footnotetext{
${ }^{5}$ Para maiores detalhes acerca da impossibilidade de alocação dos não humanos no construtivismo social da psicologia social, veja Michael (1996). Sobre a preferência da sociologia da translação pelo termo coletivo em vez do termo social, veja Latour (2001). Para este autor, coletivo se refere à associação de humanos e não-humanos, ao contrário de sociedade, que é um artefato imposto pelo acordo modernista. Peci e Alcadipani (2006) também oferecem uma base importante de contraste entre o construtivismo social e o construtivismo crítico. Este inclui tanto as críticas em relação à utilização corrente do conceito em estudos acerca, por exemplo, de gênero e imigrante, como também as limitações teóricas que a ontologia relativista impõe. É justamente na contraposição da ontologia puramente relativista que a TAR se insere como abordagem construtivista crítica.
} 
Latour e Woolgar (1997), buscando na noção de simetria a base moral de seu trabalho, também expandiram a ideia original de Bloor (1976). Diferentemente deste, Bruno Latour apresenta uma ideia de simetria que não cumpre apenas o papel de tratar, nos mesmos termos, os vencedores e os vencidos da história da ciência, mas, também, a sociedade e a natureza, a humanidade e a inumanidade (LATOUR, 2005; LATOUR e WOOLGAR, 1997). Resultante desse movimento, a TAR absorve a noção de que sociedade e natureza são constituintes do mesmo plano ontológico. Se, de modo assimétrico, é presumível considerar que apenas as pessoas podem ser agentes e "performar" o mundo, por meio da noção de simetria de Latour e Woolgar (1997); humanos e não humanos são equânimes e cúmplices na geração de agenciamentos e performatividades (MARQUES, 2006). A performatividade explica por que (algumas vezes) os fenômenos coletivos adquirem durabilidade e perenidade (LAW, 1999).

Dentro da ideia de performatividades, entidades heterogêneas são "performizadas" "nas" e "mediante" relações nas quais se inserem. A heterogeneidade é central porque permite o entendimento de que os elementos são distintos e híbridos. Exemplo disso são as ideologias, os computadores, as políticas, a pesquisa científica e uma série de outras coisas. Todas elas são formadas concomitamente por coisas e pessoas indissociáveis. Todas alcançam performatividade porque estão inscritas em redes heterogêneas de coletivos atuantes.

D’Adderio (2008) oferece um exemplo de como a noção de performatividade abre possibilidades de compreensão para os fenômenos organizacionais. A autora explora a questão da atuação das rotinas organizacionais e de como essas rotinas moldam o comportamento e a identidade das pessoas no interior das organizações. D’adderio (2008) também propõe mudar a ênfase nas "rotinas organizacionais" como objetos monolíticos para rotinas como "sistemas gerais", caracterizados por estrutura interna e dinâmica própria. Valendo-se da noção de rotinas como entidades atuantes, seria possível explorar melhor as dinâmicas da interação entre rotinas e o papel dos artefatos e das agências distribuídas. Sobre a ideia de agências distribuídas ou cognição distribuída, D’Adderio (2008) comenta que, para compreender a cognição em estado selvagem, é preciso ir além da análise do indivíduo delimitada pela pele. Como, frequentemente, a cognição envolve múltiplos seres humanos colaborando e interagindo com artefatos, decorre disso a criação de sistemas locais funcionais compostos por uma ou mais pessoas em interação com uma ferramenta cognitiva. Por meio dessa abordagem, D'Adderio (2008) demonstra que as propriedades das agências distribuídas entre humanos e não humanos são radicalmente diferentes das propriedades cognitivas de apenas uma pessoa. Vistas como artefatos dinâmicos, as rotinas são performáticas, ou seja, atuam, podendo criar e moldar o comportamento coletivo, impondo potencialidades e limitações à cognição das pessoas. Qualquer abordagem sobre a dinâmica das rotinas que descarta o papel das ferramentas e dos artefatos pode apenas prover, no máximo, um retrato parcial da realidade (D'ADDERIO, 2008).

A mesma noção de performatividade em D’Adderio (2008) está presente nos modelos e teorias científicos. Tais abstrações da realidade percebida não são meramente simples descrições. Em vez disso, essas abstrações transformam as coisas que descrevem. As pesquisas de Michel Callon (CALLON, 1986; 1999) mostram como a teoria econômica não apenas descreveu os fenômenos do mercado, mas criou o mercado como o conhecemos (CALLON, 1999; CALLON e MUNIESA, 2005). Segundo Callon (1999), o Homo economicus não é pura invenção, tampouco uma visão depreciada de uma pessoa normal. Ele realmente existe como consequência de um processo no qual a ciência econômica, como entidade performática, assume um papel ativo.

Diversos outros trabalhos inserem-se na perspectiva da TAR. De modo geral, eles compartilham a ideia da influência das materialidades relacionais, além dos aspectos relacionados com as subjetividades pessoais na construção de performatividades, embora diferenças entre subjetividades e objetividades se percam por meio da noção híbrida que a realidade assume. Há alguns exemplos desse tipo de abordagem em Garud e Karnoe (2003); Garud e Munir (2008); Parayil (2003). Garud e Karnoe (2003), por exemplo, investigam o empreendedorismo tecnológico, contrastando a ideia da descoberta com a prática da bricolagem. O tema é discutido com base no universo das agências distribuídas. Essa mesma perspectiva corrobora o argumento 
das influências circunstanciais, as quais consideram ou privilegiam não apenas os indivíduos como detentores de habilidades empreendedoras ou mesmo os contextos materiais que induzem o surgimento de iniciativas empreendedoras.

Tudo o que foi abordado abre possibilidades para a compreensão de que o empreendedorismo pode resultar de algo além de perspectivas que valorizam posições estanques. É bom explorar também a ideia de que o empreendedorismo pode ser mais bem compreendido tendo-se por base agenciamentos mutuamente subjetivos e objetivos. Essas espécies de agenciamento são impossíveis de serem purificadas.

\section{Empreendedorismo na ótica da Teoria Ator-Rede: explorando potenciais analíticos}

Por meio do foco da TAR é possível perceber outro deslocamento ontológico, além daquele definido pelos materialistas acima. Trata-se de uma alternativa às perspectivas subjetivistas e objetivistas de estudo do empreendedorismo. Isso não significa, entretanto (como bem lembra LATOUR, 1999), a superação do debate tradicional da sociologia entre agência e estrutura. Significa, em vez disso, deixar de lado as dualidades e concentrar-se nas dinâmicas híbridas que proporcionam performatividades. Essa discussão, levada ao âmbito do empreendedorismo, proporciona uma noção alternativa à compreensão dessa ação coletiva.

Da perspectiva translacional da TAR, da qual a realidade é contingente e as materialidades são relacionais, refuta-se o essencialismo na compreensão sobre como e por que surgem iniciativas empreendedoras. Isso quer dizer que não se reduz o entendimento ao se eleger um foco privilegiado para a análise das ações coletivas, quer seja sobre o indivíduo ou sobre os recursos materiais que cercam as ações humanas. Consideram-se, portanto, as iniciativas empreendedoras como resultantes de translações, as quais envolvem, conforme afirmam Garud e Karnoe (2003), agências distribuídas e tipos distintos de atores (humanos e não humanos). Cada ator adquire identidade ao se tornar entidade envolvida no processo, gerando inputs que resultam na transformação e consolidação de um determinado caminho emergente (GARUD e KARNOE, 2003). A identidade do empreendedor é, portanto, resultante das relações nas quais ele se inscreve e que são interpostas em meio à diversidade de agentes. A fabricação da identidade empreendedora não difere da ação de outras entidades que podem estar em menor evidência, como, por exemplo, as oportunidades contextuais, as tecnologias disponíveis, os stakeholders e o ambiente institucional, entre outras. Cada entidade traz consigo uma característica essencial: o hibridismo, entre pessoas e coisas, impossível de ser dissolvido. Cada uma está inscrita numa densa e dinâmica rede translacional. Todos os elementos que compõem a rede assim como a própria rede - são atuantes. A dinâmica levada a cabo por essa extensa rede de agenciamentos potencializa ou limita o surgimento de iniciativas empreendedoras (veja o box 1). 
Box 1

\section{Onde estão os empreendedores}

\section{Onde estão os empreendedores?}

Um dos argumentos principais deste artigo está na ideia de que os processos empreendedores e as redes de elementos heterogêneos que se formam em torno deles são fabricados por meio do recrutamento de uma infinidade de atores, os quais são simultaneamente humanos e não humanos, como, por exemplo, artefatos técnicos e tecnológicos, ideias, interesses e recursos financeiros. Entretanto, como o empreendedor pode assumir ou ser levado a assumir uma posição de destaque (talvez um nó) nessa rede?

Um conceito muito útil para identificar os empreendedores é o de "ponto de passagem obrigatório" (LAW e CALLON, 1992). Esse conceito se refere à associação de interesses intrínsecos das técnicas com os interesses extrínsecos do estabelecimento de relações que suportam essas práticas. A primeira associação diz respeito à criação e à consolidação de redes locais, as quais estão relacionadas diretamente com o espaço de trabalho. A segunda diz respeito às redes globais que produzem desdobramentos de relações entre atores. Elas podem ser planejadas ou podem surgir por acaso. Uma forma de mobilizar essas duas redes seria por meio dos pontos obrigatórios de passagem, os quais concentrariam a responsabilidade de articular contingências das redes locais e globais. Essa atuação no sentido de articular desafios locais específicos e interesses globais parece representar o que de fato gera empreendedores.

Fonte: Desenvolvido pelos autores

Uma importante implicação decorre desta noção de empreendedorismo. Essa implicação vai além do foco sobre a inerência ou possibilidade de desenvolvimento de habilidades vocacionais em indivíduos, ou do foco sobre as influências das condições materiais/estruturais impostas a eles pelas condições objetivas do ambiente no qual estão inseridos. Quando a existência de performatividade é levada ao âmbito da discussão, seria possível compreender, por exemplo, por que pessoas que nunca se imaginaram imersas em iniciativas empresariais são levadas a desenvolver esse papel. Esse envolvimento não pode ser explicado por meio da perspectiva subjetivista, que consideraria o sucesso ou o insucesso desses casos diretamente ligado ao fato de as pessoas manifestarem ou não características empreendedoras. Entretanto, a direção das perfomatividades que admite, tendo por base os elementos híbridos e atuantes, o surgimento de iniciativas empreendedoras é inconsistente com a versão crítica materialista, que coloca o indivíduo como eterno refém da condição a ele imposta por fatores que estão fora do seu controle. Ambos os lados simplificam sobremaneira a natureza complexa acerca da qual as ações coletivas surgem e adquirem certa estabilidade, conciliando interesses diversos em torno de movimentos mais ou menos duráveis.

Há diversos exemplos da viabilidade dos argumentos principais defendidos neste artigo. Foram escolhidos alguns estudos empíricos que focam o empreendedorismo de base tecnológica, surgidos no contexto de institutos de pesquisa. Lacetera (2006), por exemplo, em seu trabalho sobre uma série de questões relacionadas com a viabilidade dos empreendimentos lucrativos decorrentes da pesquisa científica, focaliza o sujeito pesquisador e sua própria capacidade de domínio sobre o objeto. Essa opção pode obscurecer a possibilidade de se buscar compreensão para além dos limites do indivíduo e de sua capacidade cognitiva de 
tomar decisões a favor ou contra a apropriação econômica dos resultados da pesquisa científica. Para o autor, que privilegia o foco intrínseco, poderia ser validada a hipótese da seleção adversa, na qual os melhores cientistas são os piores empreendedores e os melhores empreendedores são os piores cientistas, fato esse que, ao ser verificado, encerra um dilema vocacional impossível de ser resolvido (LACETERA, 2006).

No segundo exemplo, também vindo do ambiente da pesquisa científica, Stuart e Ding (2006) afirmam que o fato central que leva pesquisadores inseridos em universidades e institutos públicos a se envolver em atividades de pesquisa voltada para fins lucrativos está na socialização e legitimação desse comportamento no grupo social ao qual pertencem. Percebe-se, entretanto, sem prejuízo da argumentação sobre a dialética subjetividade-objetividade, que os autores compreendem esse processo de institucionalização por uma lente que foca apenas o sujeito e o grupo social. Isso tira de cena uma gama de outras entidades que o adjetivo social esconde. Exemplos delas estão na importância das pressões políticas, da qualidade das descobertas e da potencialidade das tecnologias criadas, entre outras coisas não menos importantes.

Em outro exemplo, Goldfarb, Henrekson e Rosenberg (2001) se dedicam a compreender as causas do fato de a Suíça ter sucesso relativamente menor do que os Estados Unidos nos processos de transferência de conhecimento para o mercado, mesmo sendo a Suíça um dos países que mais produzem publicações científicas por habitante. A resposta desse desempenho superior na transferência de tecnologia não estava no fato de os Estados Unidos possuírem empreendedores mais eficientes dentro dos centros de pesquisa, mas no contexto institucional, o qual permitiu a interação mais profícua entre empresas e universidades por meio da negociação de interesses diversos, particularmente pela existência ampla de elementos que atendiam às necessidades do processo empreendedor (GOLDFARB, HENREKSON e ROSENBERG, 2001). Embora esse argumento também possa ser interpretado por meio de uma visão materialista, uma leitura descritiva que considerasse as possibilidades advindas das ideias de simetria ontológica e hibridismo entre elementos humanos e não humanos certamente traria mais conteúdo compreensivo às práticas empreendedoras de base tecnológica nos dois países. Isso permitiria traçar as redes e as influências sobre as quais as performatividades se estabelecem e entender como, na prática, ocorrem as negociações e a translação dos interesses entre os atores, ou como os atuantes se transformam em atores em cada contexto.

Outro aspecto é bastante pertinente. Explorando o tema do intraempreendedorismo organizacional sob a otica da TAR, Whittle e Mueller (2008) afirmam que as ideias inovadoras florescem não porque algumas pessoas são mais empreendedoras ou mais inovativas do que outras, mas por causa dos sucessos e fracassos dos processos de inscrição em que as pessoas estão inseridas (WHITTLE e MUELLER, 2008). Nesse caso, o termo inscrição faz parte do repertório introduzido pela TAR e refere-se a

(...) todos os tipos de transformação que materializam uma entidade num signo, num arquivo, num documento, num pedaço de papel, num traço. Usualmente, mas nem sempre, as inscrições são bidimensionais, sujeitas a superposição e combinação. São sempre móveis, isto é, permitem novas translações e articulações ao mesmo tempo em que mantêm intactas algumas formas de relação. Por isso são também chamadas móveis imutáveis, termo que enfatiza o movimento de deslocamento e as exigências contraditórias da tarefa. (LATOUR, 2001, p. 350)

Acerca disso, Whittle e Mueller (2008) chamam a atenção para as dinâmicas de disseminação de novas ideias, as quais são postas em prática por meio de mediadores, os quais, com sua atuação, conseguem a inscrição de entidades a fim de manter uma rede de interesses, recursos técnicos e políticos, permitindo assim o alcance de certa estabilidade.

Embora se tenha argumentado que não se pode explicar a complexidade dos processos empreendedores buscando compreender a atuação subjetiva do sujeito, Whittle e Mueller (2008) evidenciam como a compreensão da própria identidade empreendedora é ampliada com a abordagem da TAR. Nessa ótica, a ideia do indivíduo empreendedor está muito próxima da noção de uma pessoa construtora e mantenedora de 
redes. Essas redes assumem movimentos imprevisíveis, podendo tanto legitimar ideias aparentemente ruins como eliminar ideias aparentemente boas. Tudo dependerá do movimento que os coletivos desenvolvem no decorrer das trajetórias trilhadas.

Conforme Latour (2000) afirma, a pessoa, por sua vez, luta para que o conhecimento desenvolvido adquira o status de verdade. Para isso, ela precisa de uma rede robusta de entidades, tais como: fatos científicos, equipamentos, mesas, diagramas, assistentes e aliados políticos, entre outras. A atuação da pessoa que se fabrica e é fabricada em uma rede mais ou menos estável é a mesma do empreendedor sob esse enfoque, o qual se constrói e é construído na negociação e na legitimação de uma ideia inovadora.

Considerar o empreendedorismo um produto de performatividades formadas por elementos heterogêneos e híbridos abre espaços para a exploração de algumas implicações. Uma delas, bastante pragmática, decorre do reconhecimento de que o empreendedorismo pode não ser resultante assimetricamente do comportamento dos sujeitos ou das condições dos contextos, mas de ambos simultaneamente - fruto de uma espécie de indissociabilidade simultânea. Relacionado a isso está a limitação das tentativas de se criarem mecanismos de incentivo ou, melhor, de criação de cultura empreendedora. Talvez o maior problema dessa estratégia esteja no fato de a abordagem prescritiva pertencer ao mundo da assimetria. Considerando o papel do espaço onde as iniciativas empreendedoras acontecem, há de se perceber a atuação de humanos e não humanos, simultaneamente e de modo indissociável, simetricamente formados, em parte, por pessoas e, em parte, por coisas. Quando isso é levado em conta, pode-se perder em importância a necessidade absoluta da existência de uma pessoa empreendedora ou de um contexto material, visto que iniciativas empreendedoras resultam das redes coletivas e das performatividades que decorrem dela. Quando consideradas imersas nos espaços coletivos, sempre de maneira negociada, intermediada e transformada, as iniciativas empreendedoras podem revelar que é pouco relevante o fato de a pessoa ou o ambiente apresentar ou não condições para o empreendedorismo. Isso porque a rede performática absorve o papel que, antes, caberia a uma pessoa ou ao meio no qual ela se insere.

Uma implicação metodológica é destacável. A TAR veio dos estudos de ciência e tecnologia, particularmente utilizando métodos etnográficos na observação da prática dos pesquisadores na produção dos fatos científicos. Entretanto, os objetos produção de ciência e fabricação de empreendedorismo são diferentes. Além disso, o estudo do empreendedorismo (assim como os estudos sobre inovação sugeridos por Oliveira (2008) requer a saída dos laboratórios para as redes, cuja geometria e composição são variáveis e temporárias. Cada caso de iniciativa empreendedora é um caso que pode mobilizar atores muito distintos. Por isso, o foco deixa de estar sobre a pessoa como ator empreendedor e passa a estar na própria rede como entidade que empreende iniciativas. Uma limitação para os estudos empíricos de ordem etnográfica está na dificuldade de identificar o início do processo de fabricação do empreendedor. Isso se deve à multiplicidade de elementos que fazem parte da rede na qual ele se inscreve. Ao mesmo tempo, esse fato abre a possibilidade de desvinculação dos estudos etnográficos, valorizando os estudos descritivos centrados em material documental e entrevistas (OLIVEIRA, 2008).

$\mathrm{Na}$ ordem teórica, categorias advindas da TAR possibilitam avanços na abordagem acerca do empreendedorismo - entre elas, destaca-se o conceito de simetria, desenvolvido por Bloor (1976) e generalizado por Latour e Woolgar (1997). Parafraseando Latour e Woolgar (1997), buscar compreender por que as pessoas são empreendedoras, em vez de compreender por que as pessoas não são empreendedoras, é assimétrico. Não é assim, de modo assimétrico, que o assunto é muitas vezes abordado metodologicamente e também nos cursos de estímulo ao comportamento empreendedor (Pense num empreendedor de sucesso! Agora aponte as suas características!)? A ideia de simetria oferece novas possibilidades e permite avançar para além de limitações herdadas que levam a insistir no caminho da purificação das realidades. Algo que caracteriza profundamente as realidades das práticas cotidianas é justamente o oposto disso: a impureza. A impureza, nesse caso, representa a indissociabilidade entre o social e o natural. É isso que possibilita a existência de redes sociotécnicas. 
Quando contamos as histórias das sagas empresariais depois que as caixas-pretas se fecham, sempre tendemos a privilegiar os heróis; nesse caso, os empreendedores. Entretanto, se pudermos entrar nas caixaspretas antes de elas se fecharem, assim como fez Latour (2000) quando seguiu os cientistas antes de os fatos científicos serem produzidos, talvez fosse possível perceber que, em vez de um empreendedor, existe uma infinidade de atores. Todos eles desempenham um papel crucial sem o qual seria impossível sequer construir a caixa, muito menos fechá-la. Nesse caso, não apenas os casos de sucesso, mas também os de insucesso, os que foram vencidos pela história, certamente todos podem trazer alguma luz, algumas respostas para pelo menos parte dos dilemas aqui apresentados.

A Figura 1 sintetiza os principais pontos abordados neste estudo. Ambas as perspectivas, subjetivista e objetivista, perdem sentido, uma vez que estão longe de alcançar alguns elementos aqui identificados, os quais auxiliam na compreensão acerca dos processos empreendedores na perspectiva da TAR. São eles: (i) o foco sobre as redes sociotécnicas que se constroem em torno das iniciativas empreendedoras; (ii) a indissociabilidade e simultaneidade de agência humana e não humana nos atores constituintes das redes; (iii) a preocupação com o movimento de construção em vez de o resultado daquilo que é construído.

Figura 1

\section{Síntese dos aspectos abordados no artigo}

\begin{tabular}{|c|c|}
\hline Perspectiva Subjetivista & Perspectiva Objetivista \\
\hline $\begin{array}{l}\text { Centro no individuo. } \\
\text { Abordagem economicista: o papel do } \\
\text { empreendedor na manutenção do capitalismo. } \\
\text { Abordagem comportamentalista: habilidades e } \\
\text { construção das características empreendedoras no } \\
\text { individuo }\end{array}$ & $\begin{array}{l}\text { Centro nas condições materiais impostas aos } \\
\text { individuos. } \\
\text { Empreendedorismo como fenômeno acidental e } \\
\text { circunstâncias ao acaso. } \\
\text { Empreendedorismo como resultante de estímulos } \\
\text { externos e construção dos contextos favoráveis. }\end{array}$ \\
\hline
\end{tabular}
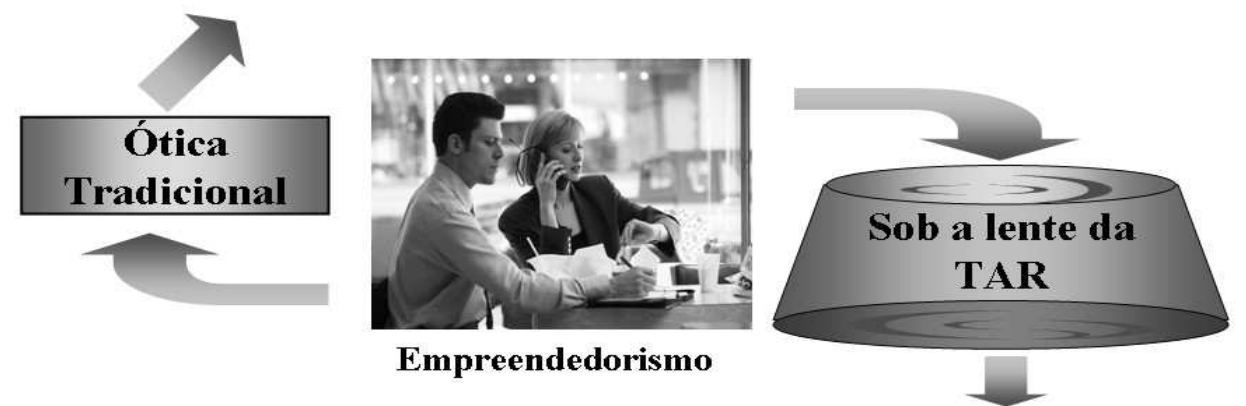

* Sai o foco da pessoa e do contexto, entra o foco das redes sociotécnicas.

* $O$ empreendedorismo passa a ser resultado de agenciamentos humanos e

não-humanos indissociáveis uns dos outros e simultaneamente simétricos.

* Mais importante do que o resultado é o processo de construção: o movimento dos atores

Fonte: Elaborado pelos autores

\section{Considerações finais}

Esta análise permitiu a exploração de algumas questões pertinentes ao avanço do empreendedorismo como tema transdisciplinar de pesquisa. Em torno da problemática fundamental, foram apontados alguns limites que a valorização de perspectivas estanques impõe à compreensão de como, realmente, ocorrem iniciativas empreendedoras. 
De modo geral, com o artigo, contribui-se para a valorização da busca de novos arcabouços que ofereçam luz a mais sobre a compreensão do empreendedorismo. Dentro das perspectivas iniciais, mesmo os mais engajados são levados a reconhecer a necessidade de se buscar novas abordagens que permitam maior coerência, especialmente quando a teoria é confrontada com a prática cotidiana da atividade empreendedora. Isso requer não apenas novas teorias, mas também novas metodologias, as quais envolvam desde a valorização dos estudos descritivos até as formas de delimitação do objeto de estudo. Especialmente acerca da metodologia, há importantes implicações porque a abordagem, ao oferecer um estatuto ontológico original, motiva um novo posicionamento diante do objeto, o que possibilita sair do que Latour chama de história-descoberta para uma história-formação (LATOUR, 1996), cuja prática oferece maior possibilidade de representar ao menos parte da complexidade que envolve a fabricação dos empreendedores por meio da reunião de atores heterogêneos em torno de uma rede comum, formada pelo recrutamento de artefatos tecnológicos, interesses políticos, instrumentos técnicos, tempo, lugar e ideologias, entre muitos outros.

Outra contribuição deste artigo está no levantamento de limitações decorrentes da permanência dentro das fronteiras impostas por visões dualistas. Isso não quer dizer que os estudos correntes tenham se tornado cegos dentro de sua visão extremamente limitada. Pelo contrário, é possível perceber a importância crescente que, por exemplo, a perspectiva subjetiva dedica à perspectiva objetiva e vice-versa. Entretanto, no presente estudo fica clara a insuficiência dessa "valorização", uma vez que o modo assimétrico de perceber as coisas não se extingue tão rapidamente quanto os preconceitos. Um exemplo desse tipo de visão dual é o reconhecimento de que tanto aspectos subjetivos como aspectos objetivos contribuem para o sucesso ou o insucesso das iniciativas empreendedoras. Esse não é o posicionamento da TAR, porque ainda trata as duas coisas de modo assimétrico. Da perspectiva da TAR, todas as entidades são híbridas, compostas ao mesmo tempo de subjetividade e de objetividade. Não dá pra separar uma coisa da outra. Humanidade e inumanidade se manifestam ao mesmo tempo por diversos meios. Esta é a diferença fundamental entre aquilo que existe na literatura habitual acerca do empreendedorismo e a visão oferecida pela lente da TAR.

Como já foi dito, por meio da TAR, talvez se perca um pouco de foco a figura da pessoa empreendedora. Isso porque o surgimento das iniciativas empreendedoras passa a ser considerado sempre como resultado de ações coletivas. Na construção dessas ações integram-se múltiplas entidades indissociáveis, simultaneamente humanas e não humanas, as quais atuam criando performatividades. Uma vez entendido dessa forma, o empreendedorismo requer a mobilização de diversos agenciamentos em torno de si, mediante o recrutamento de aliados que passam a integrar um movimento negociado, que requer translação constante de interesses. $\mathrm{O}$ descortinar desse movimento revela multiplicidade de relações e interesses políticos, sociais, econômicos, culturais, científicos e dos próprios protagonistas, que, depois da história de sucesso acontecida (históriadescoberta), habitualmente são considerados os empreendedores.

A TAR poderá contribuir para a desmistificação de uma série de limitações que habitualmente transitam ao lado das perspectivas subjetivas e objetivas. Exemplos delas estão na dificuldade de se explicar o comportamento empreendedor onde não há manifestação de características empreendedoras, no entendimento acerca do que causa comportamento espontâneo (de dentro para fora) e do que causa comportamento induzido (de fora para dentro) e na possível incompatibilidade entre abordagens prescritivas e abordagens descritivas. A prescrição, como problema, ocorre apenas no mundo da assimetria, onde objetivo e subjetivo andam separados, e a técnica reificada pretende ditar o que é bom ou não de se fazer. Recompor dicotomias e reintegrar a visão técnica e as demais permitiriam descrições multidimensionais, holísticas e atentas aos mais diversos aspectos da realidade. Daí em diante, as direções de ação emergem não mais como resultado alheio e imposto pelo empreendedor de dentro para fora, ou pelo contexto de cima para baixo, mas sim como resultado do êxito de processos coletivos de interação, interpretação, negociação e ressignificação.

Um contributo de cunho mais teórico está na crença de que a exploração desta temática cumpre o objetivo de prover explicações sobre a ação coletiva empreendedora de maneira acionável, na mesma direção elaborada por Hatchuel (2005). Do ponto de vista teórico, estas reflexões podem ser acionadas e prover novos estudos e 
futuras análises que sirvam não apenas para inspirar trabalhos empíricos, mas também possibilitar avanços importantes para o empreendedorismo como campo de conhecimento teórico e prático. Isso envolve, por exemplo, o empreendorismo social, o empreendedorismo institucional, o intraempreendedorismo, o empreendedorismo empresarial e o empreendedorismo acadêmico de base tecnológica, entre outras possibilidades.

Reconhece-se que uma limitação importante reside no fato de este estudo não apresentar resultados empíricos amplos que possibilitem os suportes analíticos para as pressuposições aqui exploradas. No entanto, abre possibilidades para futuras pesquisas empíricas, para o que, três princípios são bastante válidos (CALLON, 1986). O primeiro exige uma atitude agnóstica em relação ao tratamento que se deve dar aos atores sociais ou materiais que integram as redes investigadas. Callon (1986) afirma que isso requer que nenhum ponto de vista seja privilegiado e também que o pesquisador não fixe a identidade dos atores envolvidos se a sua identidade ainda estiver sendo negociada. $O$ segundo é a adoção da simetria generalizada. A meta, aqui, é não apenas tratar pontos de vista e argumentos conflituosos de uma controvérsia científica ou tecnológica nos mesmos termos (assim como fez David Bloor). Como explorado acima, os ingredientes das controvérsias são uma mistura simultânea de elementos vindos dos âmbitos social e natural. O terceiro se refere ao princípio da livre associação. Nesse caso, o investigador deve abandonar $a$ priori toda distinção entre eventos naturais e sociais. Isso requer a rejeição da hipótese de existência de uma fronteira definida, a qual separa os dois. A permanência da divisão é conflituosa e reflete o resultado de análises, em vez de ser a causa delas. Callon (1986) adverte para a necessidade de o investigador considerar que o repertório das categorias, as entidades as quais são mobilizadas e os relacionamentos são tópicos para discussão. Em vez de impor uma separação entre eles na análise, o investigador segue os atores com o objetivo de identificar a maneira pela qual atribuem significado e se associam a diferentes elementos por meio dos quais constroem e expandem seu mundo, seja o mundo natural ou o social.

\section{Referências}

BARROS, F. S. O.; FIÚSA, J. L. A.; IPIRANGA, A. S. R. O empreendedorismo como estratégia emergente de gestão: histórias de sucesso. Organizações \& Sociedade, v. 12, n. 33, p. 109-128, 2005.

BLOOR, D. Knowledge and social imagery. London: Routledge \& Kegan Paul, 1976.

CALLON, M. Some elements of a sociology of translation: domestication of the scallops and the fishermen of St Brieuc Bay. In: LAW, J. (Org.). Power, action and belief: a new sociology of knowledge? London: Routledge, 1986.

Actor-network theory - the market test. In: LAW, J.; HASSARD, J. (Orgs.). Actor-Network Theory and after. London: Blackwell, 1999.

CALLON, M.; MUNIESA, F. Economic markets as calculative collective devices. Organization Studies, v. 26, n. 8, p. 1229-1250, 2005.

COOPER, S. Y.; PARK, J. S. The impact of 'incubator' organizations on opportunity recognition and technology innovation in new, entrepreneurial high-technology ventures. International Small Business Journal, v. 26, n. 1, p. 27 $56,2008$.

COSTA, L. B., TORKOMIAN, A. L. V. Um estudo exploratório sobre um novo tipo de empreendimento: os spin-offs acadêmicos. Revista de Administração Contemporânea, v. 12, n. 2, p. 395-427, 2008.

CZARNIAWSKA, B. Emerging institutions: Pyramids or Anthills? Organization Studies, v. 30, n. 4, p. 423-441, 2009. 
D'ADDERIO, L. The performativity of routines: Theorising the influence of artefacts and distributed agencies on routines dynamics. Research Policy, v. 37, n. 5, p. 769-789, 2008.

DRIVER, M. New and useless - A psychoanalytic perspective on organizational creativity. Journal of Management Inquiry, v. 17, n. 3, p. 187-197, 2008.

FERRARY, M.; GRANOVETTER, M. The role of venture capital firms in Silicon Valley's complex innovation network. Economy and Society, v. 38, n. 2, p. 326-359, 2009.

GARUD, R.; KARNOE, P. Bricolage versus breakthrough: distributed and embedded agency in technology entrepreneurship. Research Policy, v. 32, n. 2, p. 277-300, 2003.

GARUD, R.; MUNIR, K. From transaction to transformation costs: The case of Polaroid's SX-70 camera. Research Policy, v. 37, n. 4, p. 690-705, 2008.

GEELS, F. W. Technological transitions and system innovations: a co-evolucionary and socio-technical analysis. Cheltenham: Edgar Elgar Publishing, Inc., 2005.

GOLDFARB, B.; HENREKSON, M.; ROSENBERG, N. Demand Vs. Supply Driven Innovations: US and Swedish Experiences in Academic Entrepreneurship. Stanford: 2001. 21. Disponível em: <http://swopec.hhs.se/hastef/papers/hastef0436.pdf> Acesso em: 22 jan. 2010.

GÖRLING, S.; REHN, A. Accidental ventures - A materialist reading of opportunity and entrepreneurial potential. Scandinavian Journal of Management, v. 24, n. 2, p. 94-102.

HATCHUEL, A. Towards an epistemology of collective action: management research as a responsive and actionable discipline. European Management Review, v. 2, p. 36-47, 2005.

HJORTH, D. Organizational entrepreneurship - With de Certeau on creating heterotopias (or spaces for play). Journal of Management Inquiry, v. 14, n. 4, p. 386-398, 2005.

HUGGINS, R. The Evolution of Knowledge Clusters Progress and Policy. Economic Development Quarterly, v. 22, n. 4, p. $277-289,2008$.

KOR, Y. Y.; MAHONEY, J. T.; MICHAEL, S. C. Resources, capabilities and entrepreneurial perceptions. Journal of Management Studies, v. 44, n. 7, p. 1187-1212, 2007.

LACETERA, N. Multiple missions and academic entrepreneurship. Boston: MIT, 2005. 47. Disponível em: <http://www.aeaweb.org/annual_mtg_papers/2006/0106_0800_1003.pdf>. Acessado em 11 de nov. 2009.

LAKATOS, I. O falseamento e a metodologia dos programas de pesquisa científica. In: LAKATOS, I.; MUSGRAVE, A. (Orgs.), A crítica e o desenvolvimento do conhecimento. São Paulo: Cultrix, 1979.

LATOUR, B. Pasteur e Pouchet: heterogénese da história das ciências. In: SERRES, M. (Org.), Elementos para uma História das Ciências. Lisboa: Terramar, 1996. v. III, p. 49-76.

On recalling ANT. In: LAW, J.; HASSARD, J. (Orgs.), Actor-Network Theory and after. London: Blackwell, 1999.

Ciência em Ação: como seguir cientistas e engenheiros sociedade afora. São Paulo: Unesp, 2000.

A Esperança de Pandora: ensaios sobre a realidade dos estudos científicos. Bauro: Edusc, 2001.

Jamais fomos modernos: ensaios de antropologia simétrica. 3ed. São Paulo: Editora 34, 2005.

LATOUR, B.; WOOLGAR, S. Vida de Laboratório: a produção dos fatos científicos. Rio de Janeiro: Relume Dumará, 1997. 
LAW, J. After ANT: complexity, naming and topology. In: LAW, J.; HASSARD, J. (Orgs.). Actor-Network Theory and after, London: Blackwell, 1999. v. 1-14

Traduction/Trahison: Notes on ANT. Lancaster: Centre for Science Studies, 2003. 15. Disponível em: <http://www.lancaster.ac.uk/fass/sociology/papers/law-traduction-trahison.pdf> Acesso em: 12 jul. 2009.

LAW, J.; CALLON, M. The life and death of an aircraft: a network analysis of technical change. In: BIJKER, W. E.; J. LAW. (Orgs.). Shaping technology/building society: studies in sociotechnical change, Cambridge, Mass.: MIT Press, 1992. p. $21-52$

MARCATI, A. GUIDO, G.; PELUSO, A. M. The role of SME entrepreneurs' innovativeness and personality in the adoption of innovations. Research Policy, v. 37, n. 9, p. 1579-1590, 2008.

MARQUES, D. B. Performatividade e agenciamentos humanos e não-humanos da realidade: uma leitura por trás da lei de biossegurança a partir da sociologia simétrica de Bruno Latour. Recife: UFPE, 2006. 302 f. Tese (Doutorado em Sociologia) - Programa de Pós-Graduação em Sociologia, Centro de Filosofia e Ciências Humanas, Universidade Federal de Pernambuco, Recife 2006.

MCCLELLAND, D. C. The achieving society. Princeton, N.J.,: Van Nostrand, 1961.

MEYER, M. Academic entrepreneurs or entrepreneurial academics? Research-based ventures and public support mechanism. R \& D Management, v. 33, n. 2, p. 107-115, 2003.

MICHAEL, M. Constructing a constructive critique of social constructionism: finding a narrative space for the nonhuman. New Ideas in Psychology, v. 14, n. 3, p. 209-224, 1996.

OLIVEIRA, L. Sociologia da Inovação: a construção social das técnicas e dos mercados. Lisboa: Celta Editora, 2008.

PARAYIL, G. Mapping technological trajectories of the Green Revolution and the Gene Revolution from modernization to globalization. Research Policy, v. 32, n. 6, p. 971-990, 2003.

PARTO, S. Innovation and Economic Activity: An Institutional Analysis of the Role of Clusters in Industrializing Economies. Journal of Economic Issues, v. 42, n. 4, p. 1005-1030, 2008.

PECI, A.; ALCADIPANI, R. Demarcação científica: uma reflexão crítica. Organizações e Sociedade, v. 13, n. 36, p. 145-161, 2006.

POZEN, D. E. We are all entrepreneurs now. Wake Forest Law Review, v. 43, p. 283-340, 2008.

REID, N.; SMITH, B. W.; CARROLL, M. C. Cluster Regions A Social Network Perspective. Economic Development Quarterly, v. 22, n. 4, p. 345-352, 2008.

SALEM, D. Uma leitura simbólica do espírito empreendedor. São Paulo: Pontifícia Universidade Católica de São Paulo, 2006.

STUART, T. E.; DING, W. W. When do scientists become entrepreneurs? The social structural antecedents of commercial activity in the academic life sciences. American Journal of Sociology, v. 112, n. 1, p. 97-144, 2006.

TOOLE, A. A.; CZARNITZKI, D. Biomedical academic entrepreneurship through the SBIR program. Journal of Economic Behavior \& Organization, v. 63, n. 4, p. 716-738, 2007.

Exploring the relationship between scientist human capital and firm performance: the case of biomedical academic entrepreneurs in the SBIR program. Management Science, v. 55, n. 1, p. 101-114, 2009.

WHITTLE, A.; MUELLER, F. Intra-preneurship and enrolment: Building networks of ideas. Organization, v. 15, n. 3, p. 445-462, 2008. 